\title{
POLÍTICA NACIONAL DE ALFABETIZAÇÃO, CURRÍCULO E GESTÃO DE RISCOS
}

\author{
Maria Carolina da Silva Caldeira \\ Universidade Federal de Minas Gerais - UFMG
}

\begin{abstract}
Resumo
Este artigo analisa a Política Nacional de Alfabetização (PNA, 2019) que se apresenta como uma proposta para elevar a qualidade da alfabetização e combater o analfabetismo no Brasil. Parte do princípio de que a PNA é em um documento curricular cujo objetivo é definir saberes e conhecimentos para serem ensinados às crianças no período da alfabetização. Nesse processo, docentes, estudantes e famílias são inseridos em relações de poder-saber, que demandam determinadas posições de sujeito. Argumenta, a partir da perspectiva pós-crítica, que esse currículo utiliza conhecimentos da "ciência cognitiva" para se afirmar como verdade a fim de gerenciar os riscos que uma população analfabeta representa. Utilizando como metodologia elementos da análise do discurso foucaultiana, o artigo mostra como esse documento desqualifica outros modos de pensar a alfabetização e os efeitos que tem nas subjetividades de docentes, familiares e crianças.
\end{abstract}

Palavras-chave: Alfabetização. Currículo. Gestão dos riscos.

\begin{abstract}
This article analyzes the National Literacy Policy (PNA, 2019) which presents itself as a proposal to raise the quality of literacy and combat illiteracy in Brazil. It starts from the principle that PNA is in a curricular document whose objective is to define knowledge and knowledge to be taught to children during the literacy period. In this process, teachers, students and families are inserted in power-knowledge relationships, which demand certain subject positions. It argues, from a postcritical perspective, that this curriculum uses knowledge from "cognitive science" to assert itself as true in order to manage the risks that an illiterate population represents. Using Foucault's discourse analysis methodology as methodology, it shows how this document disqualifies other ways of thinking about literacy and the effects it has on the subjectivities of teachers, families and children.
\end{abstract}

Keywords: Literacy. Curriculum. Risk Management.

ISSN 1645-1384 (online) www.curriculosemfronteiras.org 


\section{Introdução}

Este artigo analisa a Política Nacional de Alfabetização (PNA) promulgada por meio do Decreto n. 9.765, de 11 de abril de 2019, e o Caderno da Política Nacional de Alfabetização (Brasil, 2019), entendendo-os como políticas curriculares que pretendem instaurar uma nova lógica para as práticas de alfabetização exercidas no Brasil. Considero que esses materiais se constituem em políticas curriculares, pois estão envolvidos no processo de seleção, organização e hierarquização de saberes e conhecimentos a serem ensinados e aprendidos em instituições escolares, característica elementar da teoria curricular, como afirma Silva (2001). Com base em uma perspectiva foucaultiana, não há "saber que não suponha e não constitua ao mesmo tempo relações de poder” (Foucault, 1999, p. 27). Nesse sentido, ao organizar saberes e conhecimentos de determinada forma, essas políticas curriculares envolvem aqueles/as para os/as quais são destinadas em relações de poder. Entendo as políticas curriculares, portanto, como um artefato cultural envolvido em relações de poder-saber. Cabe registrar ainda que o poder não é compreendido apenas como algo repressivo, pelo contrário, é produtivo e um de seus principais efeitos é a produção de sujeitos. Afinal, como afirma Foucault (2000, p. 183) “o indivíduo é um efeito do poder”, ou seja, ele é produzido por meio de práticas que dividem, separam, incluem, excluem.

Esses três conceitos (saber, poder e sujeito) são importantes para o modo como compreendo currículo neste artigo: como um artefato que corporifica saberes e poderes a fim de produzir sujeitos de determinado tipo. Especificamente no que concerne à Política Nacional de Alfabetização, entendo que ela pretende formar professores/as alfabetizadores/as que balizam suas práticas em uma única verdade, afirmada como científica. Além disso, ela demanda estudantes-crianças alfabetizados/as que deixam de ser um risco aos desafios econômicos colocados pela contemporaneidade. Para isso, também demanda certa posição de sujeito para pais e mães que precisam se corresponsabilizar pela educação de seus/suas filhos/as.

A construção de uma Política Nacional de Alfabetização reflete os conflitos que ocorrem no contexto histórico atual. Afinal, como o currículo é "um espaço por excelência de experimentações, vivências e práticas, nele operam dispositivos, saberes e conhecimentos que muitas vezes evidenciam conflitos culturais, políticos e discursivos" de determinada sociedade (Caldeira; Paraíso, 2017, p. 770-771). Nesse sentido, essa política deve ser entendida no contexto dos conflitos que estão instaurados no Brasil atualmente, marcado pela perda de direitos estabelecidos, tais como o direito à aposentadoria, promovido pela Emenda Constitucional 103/2019, e a falta de investimentos na educação, expresso sobretudo pela Emenda Constitucional 55/2016.

Nesse contexto, grupos diversos têm estabelecido lutas para defender princípios considerados como garantidos até pouco tempo atrás. Trata-se, como apontam Paraíso e Ranniery (2019, p. 1.405) de um “momento assustador para todos/as nós que acreditávamos que havíamos iniciado um percurso sem volta na caminhada pela erradicação das injustiças sociais e educacionais ainda tão dramáticas no Brasil”. No âmbito da alfabetização, discussões a respeito de um método único, de metas comuns a todos/as os/as estudantes, de 
padronização das práticas docentes retornam com novo vigor. É necessário entender, então, que "a leitura da PNA - Política Nacional de Alfabetização (Brasil, 2019) precisa ser sincrônica aos acontecimentos que vêm ocorrendo no Brasil nos últimos anos, especialmente, no campo político" (Rocha; Oliveira; Santos, 2019, p. 117).

Por essa razão, compreendo a PNA como uma política reacionária e conservadora, que utiliza determinados princípios para firmar alguns conhecimentos como uma única verdade aceitável a respeito da alfabetização das crianças. Partindo de uma perspectiva foucaultiana, defendo que a PNA tem desqualificado uma série de conhecimentos historicamente construídos no âmbito das pesquisas e políticas brasileiras e que essa desqualificação tem efeitos nas subjetividades de docentes, familiares e educandos/as. Argumento, assim, que essa política curricular utiliza conhecimentos da "ciência cognitiva da leitura" para se afirmar como verdade nesse momento histórico a fim de gerenciar os riscos que uma população analfabeta representa para o país. Para o desenvolvimento desses pontos de vista, este artigo divide-se em três partes, além desta introdução. A primeira parte estabelece os elementos teórico-metodológicos que serão utilizados para a análise da PNA. Com base nos conceitos de relações de poder-saber, produção de subjetividade/modos de subjetivação e gestão de riscos, apresento as ferramentas que foram utilizadas para a produção das informações da pesquisa e para sua análise. Em seguida, mostro como a "ciência cognitiva da leitura" é apresentada como única verdade para a garantia da alfabetização de todos/as e que subjetividades são demandadas nesse processo. Por fim, teço as considerações finais articulando os elementos destacados nas análises.

\section{Ferramentas teórico-metodológicas para a análise da Política Nacional de Alfabetização}

Nossas vidas íntimas, nossos sentimentos, desejos e aspirações, parecem quintessencialmente pessoais. Vivendo num tempo em que somos rodeados por mensagens sobre problemas públicos que parecem avassaladores (guerra, fome, injustiça, pobreza, doença, terrorismo), nossos estados mentais, nossas experiências subjetivas e nossas relações íntimas aparecem como, talvez, o único lugar onde podemos localizar nossos verdadeiros eus privados. Essa crença parece, sem dúvida, muito confortável. Mas ela é profundamente enganadora. (Rose, 1998, p. 30)

A ideia corrente a respeito da subjetividade se refere ao fato de que ela se constitui no "eu profundo", naquilo que o indivíduo é essencialmente, no mais interior refúgio pessoal. Porém, com base nos chamados estudos pós-estruturalistas (ou filosofia da diferença), essa noção tem sido problematizada ao se mostrar o caráter construído da subjetividade (Silva, 1998). Nessa perspectiva, "a subjetividade (isto é, aquilo que caracteriza o sujeito) não existe nunca fora dos processos sociais, sobretudo de ordem discursiva, que a produzem como tal" (Silva, 1998, p. 10). Nesse sentido, outros termos têm sido acionados para falar dos processos 
de constituição do eu, como posições de sujeito, práticas subjetivadoras ou modos de subjetivação. É com base nesse ponto de vista que analiso de que modo uma política curricular tal como a PNA tem demandado e produzido modos de ser e estar no mundo considerados como mais adequados para professores/as e estudantes.

Para Foucault (1998, p. 10), os modos de subjetivação são produzidos na relação entre a “formação dos saberes que a ele se referem, os sistemas de poder que regulam sua prática e as formas pelas quais os indivíduos podem e devem se reconhecer como sujeitos”. O processo de produção de sujeitos refere-se, então, ao modo como os saberes se organizam para nomeálos, às relações de poder que se estabelecem entre eles e às práticas de si que o sujeito é levado a fazer sobre si mesmo a fim de se constituir de determinadas maneiras. Portanto, analisar o modo como uma política curricular atua na produção de sujeitos pressupõe compreender de que maneira esses três eixos se articulam e que demandas são feitas para aqueles/as que são interpelados/as por tais políticas.

Na perspectiva aqui adotada, o saber se caracteriza como um "conjunto de elementos, formados de maneira regular por uma prática discursiva e que são indispensáveis à constituição de uma ciência, apesar de não se destinarem necessariamente a lhe dar lugar” (Foucault, 1972, p. 220). Saberes se referem a elementos que funcionam dentro de determinado discurso estabelecendo disputas entre o verdadeiro e o falso e demandando determinados modos de se comportar. Os saberes incluem conhecimentos considerados como científicos, mas não se limitam a eles, já que abarcam tudo aquilo que, em determinado discurso, entra na disputa pela verdade e pela produção de sujeitos. O saber também se refere ao espaço em que o sujeito "pode tomar posição para falar dos objetos de que se ocupa em seu discurso” (Foucault, 1972, p. 221).

A pesquisa realizada neste artigo utiliza como metodologia elementos da análise do discurso de inspiração foucaultiana para compreender os efeitos da PNA. A análise do discurso, nessa perspectiva, tenta “escapar da fácil interpretação daquilo que estaria por trás dos documentos, procurando explorar ao máximo os materiais, na medida em que eles são uma produção histórica, política; na medida em que as palavras são também construções” (Fischer, 2001, p. 199). Procura compreender que jogos de poder se estabelecem no discurso, pois parte-se do princípio de que eles deixam marcas nos materiais na medida em que a linguagem também é constitutiva de práticas. Por essa razão, considero que o discurso “produz sistematicamente os objetos sobre os quais fala” (Foucault, 1972, p. 64) e, nesse sentido, ele é considerado como tendo efeitos específicos sobre os saberes e sobre os indivíduos que são interpelados por ele.

A análise do discurso não pode ser desvinculada da compreensão das relações de poder. Afinal, como afirma Foucault (1996, p. 2), "suponho que em toda a sociedade a produção do discurso é simultaneamente controlada, selecionada, organizada e distribuída por um certo número de procedimentos que têm por papel exorcizar-lhe os poderes e os perigos”. Há diversos mecanismos em operação que têm como objetivo fazer com que poucas coisas possam ser ditas em determinados contextos. Assim, analisar discursos é também verificar os procedimentos que fazem com que, entre os muitos saberes que podem ser acionados, efetivamente pouca coisa seja dita (Foucault, 1972), procurando compreender os 
procedimentos de rarefação e as relações de poder que se estabelecem para limitar a multiplicidade de discursos.

Na visão de Foucault (2000, p. 183), o poder não é exclusivamente repressivo ou de mão única. Ele não deve ser compreendido como "um fenômeno de dominação maciço e homogêneo de um indivíduo sobre os outros, de um grupo sobre os outros, de uma classe sobre as outras”. Pelo contrário, o poder é difuso, descentralizado, está presente nas diversas esferas sociais. Ele "nunca está localizado aqui ou ali, nunca está nas mãos de alguns, nunca é apropriado como uma riqueza ou um bem” (Foucault, 2000, p. 183). Na teorização póscrítica de currículo, compreende-se o poder "em sua positividade, como produtor de verdades, de subjetividades, de saber” (Paraíso, 2007, p. 54). Analisar discursos considerando o poder dessa maneira significa perseguir os efeitos produtivos que ele tem. Significa verificar que saberes são incluídos e quais são excluídos, por meio de quais procedimentos determinadas autoridades são estabelecidas e de que forma são criadas posições que os diferentes sujeitos (estudantes, professores/as, familiares) podem e devem ocupar para serem reconhecidos como sujeitos desse discurso.

Nesse sentido, metodologicamente, ao analisar a Política Nacional de Alfabetização e o Caderno que a divulga, procurei estar atenta aos seguintes elementos: a) quem pode falar nesse documento?; b) que autoridades são estabelecidas?; c) que procedimentos são utilizados para desqualificar certos saberes e afirmar outros?; d) a que urgência do momento contemporâneo esse documento pretende responder?; e) que posições de sujeito são estabelecidas para docentes, estudantes e famílias nesse currículo?

A partir dessas questões, foi realizada a análise do discurso no documento. Por meio dela, foi possível perceber que a PNA está imersa em relações de poder-saber que se preocupam com a gestão da vida daqueles/as que vivenciam o currículo da alfabetização. Essa ideia aproxima-se do conceito de biopoder. Segundo Foucault (2006, p. 131), na modernidade, "o poder político acabava de assumir a tarefa de gerir a vida" (Foucault, 2006, p. 131). Para isso, foi necessário fazer com que a vida entrasse "no domínio dos cálculos explícitos” (Foucault, 2006, p. 155).

Uma série de estratégias passaram a ser consideradas importantes para evitar que a vida não fosse vivida de acordo com os critérios estabelecidos por relações de poder. Nesse processo de gerenciamento da vida, é necessário classificar espaços e indivíduos, verificando se há certas características que podem ser problemáticas. Essas características passam a ser nomeadas como "risco". De modo geral, os riscos de determinados grupos populacionais "estão relacionados à sua suposta improdutividade e/ou impossibilidade de gerenciar sua própria vida” (Lockmann, 2020, p. 69). Por isso, é necessário que o poder aja de maneira mais ostensiva sobre tais riscos, a fim de governar a vida desses indivíduos. Segundo Traversini (2003, p. 111), "com a invenção da noção de risco, passou-se a considerar que algumas ações podem ser realizadas para prevenir e evitar perigos e ameaças, obtendo uma sensação de domínio da insegurança e da incerteza”.

Historicamente, o analfabetismo tem sido considerado como um grande fator de risco para diferentes populações. Por essa razão, variadas propostas que visam acabar com 0 analfabetismo em nosso país ${ }^{1}$ têm sido criadas ao longo dos séculos XX e XXI. Nesse 
contexto, a Política Nacional de Alfabetização pode ser compreendida como uma estratégia para minar os riscos que uma população analfabeta representa. Apesar do objetivo aparentemente nobre dessa política, é preciso considerar que, como aponta Mortatti (2019, p. 26), essa política representa uma “"guinada’ (ideo) metodológica para trás e pela direita” que visa desqualificar determinados modos de pensar a alfabetização e que não pode ser compreendida fora do "projeto político-ideológico neoliberal e ultraconservador do atual governo federal e está estrategicamente articulada às demais medidas de destruição dos avanços democráticos conquistados pela população brasileira nas últimas décadas” (Mortatti, 2019, p. 26). Considerando tais elementos, mostro, a seguir, como, ao desqualificar saberes e conhecimentos historicamente construídos no campo da alfabetização, essa política inserese no processo atualmente em curso de negar certos saberes e estabelecer modos únicos de gerenciar a vida, o currículo e a escola.

\section{A ciência cognitiva da leitura como verdade: os saberes estabelecidos como verdadeiros para a alfabetização de crianças}

Os excertos a seguir foram retirados do Caderno da Política Nacional de Alfabetização e evidenciam como esse currículo procura legitimar-se tendo como base uma das formações discursivas mais significativas de nosso tempo: a Ciência. Veja-se.

A maioria dos países que melhoraram a alfabetização nas últimas décadas fundamentaram suas políticas públicas nas evidências mais atuais das ciências cognitivas, em especial da ciência cognitiva da leitura (ACADEMIA BRASILEIRA DE CIÊNCIAS, 2011). Essa área do conhecimento apresenta o conjunto de evidências mais vigorosas sobre como as pessoas aprendem a ler e a escrever e como é possível ensiná-las de modo mais eficaz. (Brasil, 2019, p. 16)

A PNA pretende inserir o Brasil no rol de países que escolheram a ciência como fundamento na elaboração de suas políticas públicas de alfabetização, levando para a sala de aula os achados das ciências cognitivas e promovendo, em consonância com o pacto federativo, as práticas de alfabetização mais eficazes, a fim de criar melhores condições para o ensino e a aprendizagem das habilidades de leitura e de escrita em todo o país. (Brasil, 2019, p. 7)

Entre os ramos das ciências que mais contribuíram nas últimas décadas para a compreensão dos processos de leitura e de escrita, está aquele que se convencionou chamar ciência cognitiva da leitura. (Brasil, 2019, p. 21)

Nos últimos três séculos, conhecimentos nomeados como científicos passaram a gozar de status e realizaram a desqualificação de outras formas de pensar. Como afirma Santos (2007, p. 10), a "racionalidade científica é também um modelo totalitário, na medida em que nega o caráter racional a todas as formas de conhecimento que não se pautarem pelos seus 
princípios epistemológicos e pelas suas regras metodológicas”. Nesse sentido, a ênfase dada à ciência cognitiva no texto da PNA insere-se na lógica que utiliza a estratégia de nomear-se como científica para afirmar-se como verdade, negando outros conhecimentos. Ao mesmo tempo, ela apresenta essa verdade autonomeada científica como a única capaz de colocar o Brasil no rol de países que conseguiram promover a melhora da qualidade da alfabetização.

Contudo, esses excertos também podem causar alguma confusão. Afinal, nos últimos anos, há um grande descaso do governo atual com a Ciência, expresso por meio de cortes significativos em diferentes âmbitos ${ }^{2}$ e, especificamente, de posicionamentos diante do contexto da pandemia da COVID-19: falas de diferentes entes do governo desqualificam a Ciência e negam a existência ou a gravidade da doença. ${ }^{3}$ Verdades científicas consideradas como certas, como o fato de que a Terra não é plana ou de que a teoria da evolução pode ser provada, são rechaçadas e afirma-se que não passam de opinião (Paraíso, 2019). Como entender, então, uma política que utiliza justamente a Ciência para se afirmar?

Ellsworth (2001, p. 23), ao analisar como funcionam os filmes hollywoodianos, afirma que "diferentes sistemas formais e estilísticos, presentes em um único filme, podem ter diferentes modos de endereçamento. Podem estar ocorrendo, de forma simultânea, múltiplos modos de endereçamento". Considerando o modo de endereçamento como as estratégias utilizadas para que determinado discurso interpele um determinado grupo de pessoas, é necessário multiplicar as entradas para que esse discurso possa ser acessível ao maior número de indivíduos. No caso de uma política curricular em nível federal, parece ser necessário utilizar-se da baliza científica a fim de garantir certa adesão por parte dos/as docentes e entes federados aos quais a política se destina. Afinal, esse currículo entra em disputa com outros já existentes e que também se utilizavam de estudos e pesquisas para construir seus argumentos. Para afirmar-se, é necessário inserir-se nessa mesma lógica, a fim de desqualificar as outras ciências que disputam lugar no verdadeiro da alfabetização.

A PNA afirma, então, a ciência cognitiva como a mais atual forma de pensar a alfabetização e a única capaz de promover o avanço na alfabetização. Segundo o documento, "por ciência cognitiva se designa o campo interdisciplinar que abrange as diferentes disciplinas que estudam a mente e sua relação com o cérebro, como a psicologia cognitiva e a neurociência cognitiva” (Brasil, 2019, p. 20). A ciência cognitiva pode ser compreendida como o vasto campo de conhecimento que opera com algumas técnicas oriundas do campo da psicologia e que recorrem a esse campo de saber para produzir um modo específico de subjetivação (Silva, 1998; Rose, 1998; 2001).

Um dos procedimentos utilizados na PNA para afirmar-se como verdade refere-se ao fato de que ela homogeneíza a ciência cognitiva, particularmente a ciência cognitiva da leitura. Em um box explicativo, o documento questiona: "Como saber se uma pesquisa apresenta uma evidência científica válida?” Na sequência, são elencados os princípios validadores dessa perspectiva, como se pode ver no recorte a seguir (Figura 1): 
Figura 1 - “Como saber se uma pesquisa apresenta uma evidência científica válida”

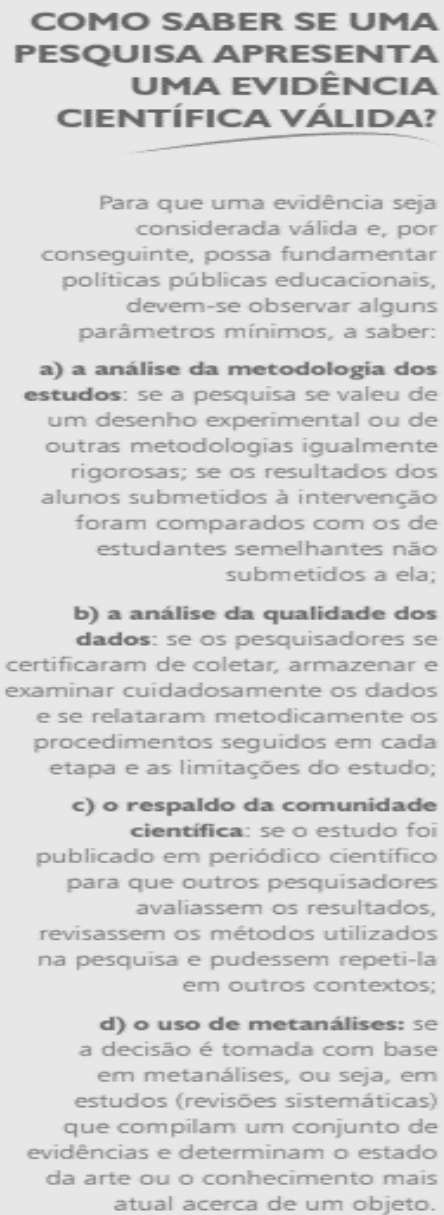

Fonte: Caderno da Política Nacional de Alfabetização (Brasil, 2019, p. 20)

Um único modo de fazer ciência é tido como verdadeiro nesse currículo. Dá-se a entender que toda a ciência cognitiva opera da mesma maneira e que estabelece os mesmos princípios para afirmar-se como verdade. Rose (2010, p. 309) aponta um estudo que levantou o número de periódicos que existiam há uma década, no mundo, sobre as "ciências do cérebro". Segundo ele, "há cerca de 350 a 400 revistas sobre as novas ciências do cérebro que você teria que examinar se quisesse traçar o que está ocorrendo no discurso especialista e, apenas em 2008, mais de 26.000 artigos foram publicados nessas revistas”. Scliar-Cabral (2019, p. 279), por sua vez, ao analisar a PNA, afirma que há "desatualização dos autores da proposta a respeito das contribuições mais recentes das ciências cognitivas, em especial, da neurociência da leitura”. Tal fato parece indicar que há diferentes perspectivas no que se refere à ciência cognitiva, aspecto ignorado por esse currículo que, ao usar o procedimento da homogeneização, ignora e silencia toda a diversidade que existe no próprio campo da ciência cognitiva. 
De modo semelhante, também se dá a entender que apenas os modos da ciência cognitiva são válidos e que outros modos de pensar a alfabetização não são científicos ou não produzem evidências, de acordo com os critérios estabelecidos na PNA. Desconsidera-se toda a produção acadêmica em educação relacionada à alfabetização de crianças nos anos iniciais do Ensino Fundamental. Maciel (2019) refere-se à pesquisa "Alfabetização no Brasil: estado do conhecimento", realizada pelo Centro de Alfabetização Leitura e Escrita da Faculdade de Educação da UFMG, que conta em sua base de dados com "1924 teses e dissertações produzidas sobre alfabetização de crianças no Ensino Fundamental, ao longo de 40 anos. Desse conjunto, a produção sobre alfabetização nos cursos de pós-graduação em Educação cresceu e ultrapassou a produção acadêmica dos programas de Psicologia” (Maciel, 2019, p. 59). Há uma vasta produção a respeito da alfabetização que é desconsiderada pela PNA em prol da afirmação da ciência cognitiva da leitura como única verdade. Fato semelhante ocorre em torno da produção acadêmica acerca do letramento que também é desconsiderada na PNA, como mostra o estudo de Bunzen (2019).

A desconsideração quanto à produção no campo da educação e a predominância de saberes da chamada ciência cognitiva também se apresenta na seleção dos experts que são autorizados a falar nesse documento. No Caderno da PNA, há boxes explicativos nas laterais da página, a maior parte desses intitulados "O que dizem os especialistas". São 15 explicações de especialistas em 37 páginas de documento. A maioria deles/as são apresentados/as como tendo o título de doutores/as que atuam em universidades do Brasil e internacionais. Nas páginas iniciais do documento é apresentada também a composição da Equipe que elaborou o documento, composta por 21 membros. Maciel (2019, p. 58) afirma que, "nessa Equipe, constam 13 especialistas cuja formação e atuação principal são na área da Psicologia, 2 na área da Linguística e 5 na Educação”. Aparece aqui também outro procedimento que funciona nesse discurso para afirmar uma determinada verdade: $o$ recurso aos/às experts.

Nas relações de poder-saber contemporâneas, as autoridades têm fundamental importância, pois "cumprem a função no discurso de fazer diversas tentativas para agir sobre as ações dos outros, em nome de objetivos ligados à prosperidade nacional, produtividade, felicidade" (Paraíso, 2007, p. 187). Para se afirmar, "a autoridade da autoridade depende de uma presunção de saber positivo, de sabedoria e virtude, de experiência e julgamento prático" (Rose, 2001, p. 39). Recorre-se, na escrita da PNA, à autoridade vinculada a certas instituições universitárias (em sua grande maioria internacionais e notadamente estadunidenses) e aos títulos acadêmicos como estratégia para mostrar a neutralidade e a superioridade desse saber.

Parece operar aqui uma expertise que tem se tornado fundamental nas relações de podersaber. Isso ocorre "não porque os experts conspiram com o estado para iludir, controlar e condicionar os sujeitos” (Rose, 1998, p. 42). Pelo contrário, o que eles/as fazem é agir sobre escolhas, desejos e condutas. Operam, assim, "não através da ameaça da violência ou do constrangimento físico, mas através da persuasão inerente às suas verdades, das ansiedades estimuladas por suas normas e das atrações exercidas pelas imagens da vida e do eu que ela nos oferece” (Rose, 1998, p. 43). Afinal, que professor/a não sonha com uma criança 
alfabetizada? Que docente e/ou pesquisador/a ousa discordar da importância do acesso à cultura escrita para as crianças, sobretudo para as mais pobres? Quem não deseja garantias quanto aos modos como as crianças aprendem e o melhor meio de ensiná-las? A PNA reconhece e dialoga com esses desejos aos estabelecer quem pode falar nesses documentos. Nesse processo, esse currículo demanda subjetividades docentes que utilizam conhecimentos apresentados como científicos e baseados em evidências para alfabetizar seus/suas alunos/as.

Ao analisar as autoridades que são estabelecidas nesse documento, Morais (2019, p. 66) afirma que, "sem nenhum debate, empresários e especialistas, que desde 2003 queriam impor o método fônico como única forma de alfabetizar, se aliaram a um governo nada democrático, para contrariar esse direito constitucional” de livre escolha da metodologia a ser utilizada nas escolas. Ao apresentar a ciência cognitiva da leitura como única forma de garantir que todos/as se alfabetizem, a Política Nacional de Alfabetização estabelece também que saberes devem ser ensinados para as crianças. Na visão de Morais (2019), ela estabelece um “como”, o que contraria o preceito estabelecido na Constituição Federal, do "pluralismo de ideias e de concepções pedagógicas” (Brasil, 1988, art. 206, inciso III). ${ }^{4}$

No que se refere aos saberes, a PNA estabelece "cinco componentes essenciais para a alfabetização, a saber: a consciência fonêmica, a instrução fônica sistemática, a fluência em leitura oral, o desenvolvimento de vocabulário e a compreensão de textos” (Brasil, 2019, p. 32). Na sequência, o documento também informa que "pesquisas mais recentes, no entanto, recomendam a inserção de outro componente, a produção escrita". Com essa inclusão, "se obtêm os seis componentes propostos pela PNA, nos quais se devem apoiar os bons currículos e as boas práticas de alfabetização baseada em evidências” (Brasil, 2019, p. 32). Como pilares que são, esse conjunto de saberes produziria a alfabetização, tal qual demonstrado na Figura 2 a seguir, apresentada no documento:

Figura 2: Saberes necessários à alfabetização

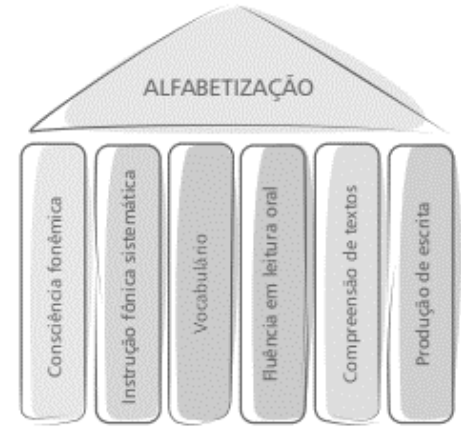

Fonte: Política Nacional de Alfabetização (Brasil, 2019, p. 33)

A imagem da casa parece ser acionada aqui para mostrar que saberes são essenciais nesse processo. Se em outros documentos curriculares já havia uma preocupação em definir os conhecimentos e saberes necessários à alfabetização, parece haver na PNA uma clara restrição do que e como deve ser o ensino nessa etapa da escolarização, diferentemente do que ocorria em políticas curriculares para a alfabetização anteriores. Analisando o Pacto 
Nacional pela Alfabetização na Idade Certa (Brasil, 2013), Frangella (2016) mostrava como os elementos presentes nessa política de formação de professores/as deram subsídios para o estabelecimento da Base Nacional Comum Curricular no que concerne à alfabetização. Na visão da autora, já havia no documento um modo limitado de compreender currículo que considerava que o "silenciamento em torno do conhecimento tomado como dado e sua uniformização em nome da igualdade leva a uma perspectiva em que a discussão curricular se encerra na gradação da aprendizagem e em decisões de caráter metodológico” (Frangella, 2016, p. 85). Apesar dessa crítica, a autora mostra que havia ali uma preocupação em garantir diversidade quanto aos saberes e conhecimentos acionados nesse currículo, que incluía questões relativas ao "letramento, baseada em práticas sociais de leitura e escrita, ultrapassando em sua conceituação e discussão a lógica instrumental do aprender a ler e escrever" e a consideração por "elementos importantes - como a singularidade da infância , a necessidade de remeter a práticas extraescolares, à diversificação de material”. Todas essas discussões são eliminadas da Política Nacional de Alfabetização e se considera que a instrução fônica é a forma mais eficaz de promover a alfabetização.

Embora não se afirme explicitamente que o método fônico deva ser adotado nas escolas, os saberes considerados importantes de serem ensinados remetem a ele. Nesse sentido, a explicação dos seis pilares para a alfabetização mostra essa importância. Assim, a consciência fonêmica é definida como "conhecimento consciente das menores unidades fonológicas da fala (fonemas) e a capacidade de manipulá-las intencionalmente. Para desenvolver a consciência fonêmica, é necessário um ensino intencional e sistematizado” (Brasil, 2019, p. 33). Nessa perspectiva, o/a professor/a alfabetizador/a deve ensinar que "a língua é composta desses pequenos sons”, chamados fonemas (Adams; Fooman; Lundberg, Beeler, 2006, p. 19). Além disso, deve ensinar explicitamente as relações entre sons (fonemas) e letras (grafemas), processo nomeado de “Instrução fônica sistemática”. O/a alfabetizador/a também deve trabalhar para ampliar o vocabulário das crianças, já que “um vocabulário pobre constitui um obstáculo para a compreensão de textos” (Brasil, 2019, p. 34). A "fluência na leitura" também deve ser buscada por esse/a docente, que deve trabalhar considerando o número médio de palavras lidas pelo/a educando/a por minuto, de acordo com a Tabela 1 a seguir:

Tabela 1 - Número médio de palavras lidas por minuto, de acordo com a PNA

\begin{tabular}{|c|c|}
\hline Ano do ensino fundamental & $\begin{array}{c}\text { Número médio de palavras } \\
\text { lidas por minuto }\end{array}$ \\
\hline $1^{\circ}$ & 60 \\
\hline $2^{\circ}$ & 80 \\
\hline $3^{\circ}$ & 90 \\
\hline $4^{\circ}$ & 100 \\
\hline $5^{\circ}$ & 130 \\
\hline
\end{tabular}

Fonte: Política Nacional de Alfabetização (Brasil, 2019, p. 34) 
Por fim, há dois saberes que não se relacionam diretamente à aquisição do código escrito. Trata-se da "Compreensão de textos” e da "Produção escrita”. No documento, registra-se que “a compreensão não resulta da decodificação. São processos independentes”. Todavia, também se define que "a capacidade de decodificação [...] é determinante para a aquisição de fluência em leitura e para a ampliação do vocabulário, fatores que estão diretamente relacionados com o desenvolvimento da Compreensão” (Brasil, 2019, p. 34). A escrita, por sua vez, refere-se tanto à escrita de palavras quanto à produção de textos mais longos. Segundo esse currículo, "para crianças mais novas, escrever ajuda a reforçar a consciência fonêmica e a instrução fônica. Para crianças mais velhas, a escrita ajuda a entender as diversas tipologias e gêneros textuais” (Brasil, 2019, p. 34). Apesar de distintos do processo de codificar e decodificar, o modo como tais saberes são apresentados subordina-os às questões da consciência fonêmica e da instrução fônica, reforçando a importância de tais saberes e subordinando o uso da língua em situações reais a essas aprendizagens.

Dessa forma, ainda que o documento ressalte que "não se deve confundir a instrução fônica sistemática com um método de ensino” (Brasil, 2019, p. 33) ou que “o uso dos métodos fônicos, por si só, não irá resolver o problema da alfabetização” (Brasil, 2019, p. 17), há nessa política um modo de compreender o processo de alfabetização que a aproxima dos métodos fônicos. Isso se evidencia pela predominância que os saberes desse método apresentam na proposta de currículo para a alfabetização estabelecida. ${ }^{5}$ Parece que esse documento reativa a chamada “querela dos métodos", que está presente em nosso país desde o século XIX (Mortatti, 2000). Embora busque utilizar “as mais recentes evidências científicas”, o que essa política faz é reacender uma discussão que dura mais de cem anos, na qual parece haver uma “contínua alternância entre 'inovadores' e ‘tradicionais': um 'novo' método é proposto, em seguida é criticado e negado, substituído por outro 'novo' que qualifica o anterior de 'tradicional'” (Soares, 2018, p. 23, destaques da autora). Nesse momento, a chamada "ciência cognitiva da leitura” aparece como a grande inovação para combater o grande problema do analfabetismo em nosso país, embora ela acione os elementos dos métodos fônicos e reatualize a disputa entre métodos já tão antiga.

O risco do analfabetismo aparece como o terceiro procedimento adotado na Política Nacional de Alfabetização para afirmar-se como verdade nesse momento histórico. De acordo com a PNA, “o analfabetismo nos dias atuais está claramente associado a condições adversas de vida, geralmente relacionadas à pobreza e geradoras de diferentes formas de vulnerabilidade sociais” (Brasil, 2019, p. 10). Por essa razão, o objetivo central da Política Nacional de Alfabetização é "elevar a qualidade da alfabetização e combater o analfabetismo em todo o território brasileiro” (Brasil, 2019, p. 7). Parece operar nesse documento a ideia de que "as pessoas são analfabetas, portanto, seu processo cognitivo é inferior, seu desenvolvimento econômico é prejudicado" (Street, 2010, p. 36). O preconceito contra os/as analfabetos/as é uma realidade construída na sociedade brasileira por meio de diferentes estratégias e que parece ser reativada pela PNA. Nela "os analfabetos foram (e continuam sendo) narrados como indivíduos pouco produtivos, explorados, excluídos da sociedade, que se sentem envergonhados pela sua condição” (Traversini, 2009, p. 578). 
Nesse sentido, o analfabetismo é apresentado como um risco para um grupo de crianças, particularmente aquelas que não dispõem do que é nomeado no documento como "literacia familiar", definida como o "conjunto de práticas e experiências relacionadas com a linguagem, a leitura e a escrita, as quais a criança vivencia com seus pais ou cuidadores" (Brasil, 2019, p. 51). Por não terem acesso às práticas da cultura escrita em suas famílias, essas crianças precisam da escola e de ações voltadas à aquisição do código escrito, para evitar que permaneçam analfabetas. Precisam, também, que suas famílias assumam certas posições a fim de combater os riscos do analfabetismo.

As crianças pobres que podem não se alfabetizar são aqui entendidas como uma população. Para Foucault (2006, p. 31), a partir do século XVIII "os governos percebem que não têm que lidar simplesmente com sujeitos, nem mesmo com um 'povo', porém com uma 'população', com seus fenômenos específicos e suas variáveis próprias”. Trata-se, assim, de delimitar as características de um determinado grupo e, a partir delas, pensar em políticas gerais e em formas de exercer poder sobre eles/as. Como afirmam Bello e Traversini (2009, p. 144), "em uma comunidade pode haver indivíduos ou um grupo deles que não se enquadram nas características consideradas de risco", porém, para o exercício do poder sobre a população, tais diferenças pouco importam. O que vale, nesse momento é produzir “exercícios de gestão de riscos" (Bello; Traversini, 2009, p. 144) que modelem essa população a uma meta preestabelecida.

Para isso, a estatística funciona como um saber fundamental que possibilita mostrar os riscos que o país corre caso a alfabetização não se consolide. Ela é acionada para estabelecer as metas para a população infantil que se quer governar. Na PNA, os dados da Avaliação Nacional da Alfabetização (ANA), do Pisa e do Inaf (Indicador de Alfabetismo Funcional) são acionados por meio de percentuais e tabelas, a fim de evidenciar o quanto ainda temos "problemas" no campo da alfabetização, como se vê na imagem (Tabela 2) a seguir.

Tabela 2 - Dados sobre analfabetismo

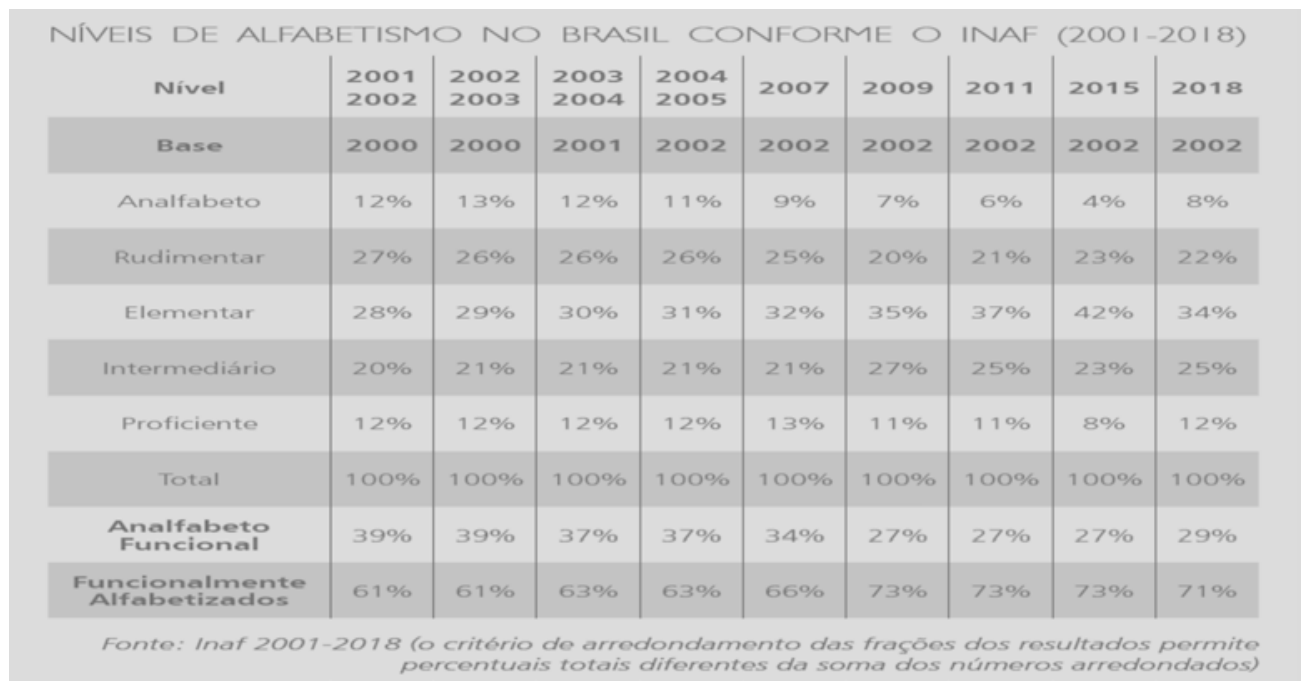

Fonte: Política Nacional de Alfabetização (Brasil, 2019, p. 13) 
A estatística é acionada para exercer poder sobre docentes e crianças. É para evitar que a insuficiência nos níveis de leitura se mantenha, para impedir que continuemos a ocupar o $59^{\circ}$ lugar entre os países avaliados pelo Pisa e para resolver o problema dos "7,0 pontos percentuais [que ainda faltam] para a erradicação do analfabetismo absoluto” (Brasil, 2019, p. 12), que esses dados são apresentados. Não por acaso, eles estão logo no início desse documento. A apresentação de dados numéricos pretende dar um caráter de verdade incontestável à situação precária no que se refere à alfabetização que vivemos no país, de acordo com esse documento, já que "os números permitem um planejamento administrativo" (Bello; Traversini, 2009, p. 144) de determinadas situações. Eles fazem com que certos aspectos da "vida e de seus mecanismos entrem no domínio dos cálculos explícitos, e faz do poder-saber um agente de transformação da vida humana” (Foucault, 2006, p. 155-156). É necessário medir o desempenho das crianças e conduzir suas vidas de maneira a evitar que elas caiam no risco do analfabetismo a que sua baixa literacia familiar conduziria. Diante de tal argumentação, parece ser preciso pensar uma política que venha para combater um risco que as crianças pobres correm, caso medidas específicas não sejam tomadas. Desse modo, define-se a posição de sujeito “criança alfabetizada” como uma demanda desse discurso. É necessário que as crianças se alfabetizem e, preferencialmente, que façam isso o quanto antes, ainda no primeiro ano do Ensino Fundamental. ${ }^{6}$

Para que isso ocorra, é necessário garantir que os/as professores/as sigam certos preceitos e que baseiem suas práticas nas evidências científicas da ciência cognitiva. Porém, é necessário também “conduzir as condutas” (Foucault, 1997) das famílias. Os pais e mães precisam contribuir com o que é chamado de "literacia familiar", as "práticas e experiências relacionadas à linguagem, à leitura e à escrita que elas vivenciam com seus pais, familiares ou cuidadores, mesmo antes do ingresso no ensino formal” (Brasil, 2019, p. 23). Para reforçar a importância do governo da família para evitar o risco do analfabetismo, cita-se o fenômeno conhecido como “Efeito Mateus” (Figura 3):

Figura 3: Efeito Mateus

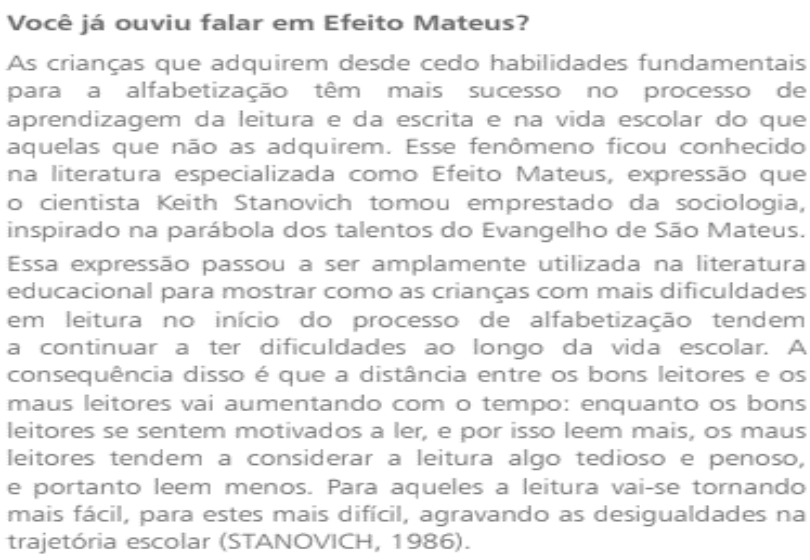

Fonte: Política Nacional de Alfabetização (Brasil, 2019, p. 23) 
A história parte da passagem bíblica registrada no Evangelho de São Mateus (Mateus 25:29) segundo a qual "a quem tem, mais lhe será confiado, e possuirá em abundância. Mas a quem não tem, até o que tem lhe será tirado". É assim que se justifica a necessidade de que as famílias envolvam as crianças em práticas de literacia desde muito cedo, visando ampliar sua inserção no mundo da escrita e garantir que elas tenham algo para que ganhem ainda mais ao ingressarem na escola. Demanda-se a posição de sujeito "pai/mãe responsável pela alfabetização”. Essa é uma posição que não pode ser exclusiva para as famílias de classe média, afinal "até mesmo pais ou cuidadores não alfabetizados podem realizar práticas simples e eficazes de literacia familiar quando bem orientados” (Brasil, 2019, p. 23). É necessário que as famílias mais pobres assumam tal posição pois "os principais beneficiários são as famílias de nível socioeconômico mais baixo, cujas crianças se encontram em desvantagem com relação às demais” (Brasil, 2019, p. 23). Assim, as famílias são corresponsabilizadas no processo de alfabetização de seus/suas filhos/as e devem assumir essa tarefa junto com as escolas a fim de evitar os riscos que uma população infantil analfabeta pode representar ao país.

\section{Considerações finais}

Retomo aqui algumas questões a fim de sintetizar as análises que empreendi anteriormente. Ao analisar a Política Nacional de Alfabetização, procurei demonstrar quem pode falar nesse documento e que autoridades são estabelecidas. Parece que, em uma perspectiva antidemocrática, como aponta Morais (2019), esse documento silencia todos/as aqueles/as que não falam conforme o que está estabelecido na chamada "ciência cognitiva da leitura". Somente aqueles/as que falam conforme esse saber - e conforme uma parcela bastante específica desse saber - que se apresenta como única verdade são reconhecidos e se constituem como "autoridades".

Essa análise permitiu mostrar também que saberes são desqualificados nesse processo. Aqueles/as pesquisadores/as que se utilizam de inúmeras outras formas de pensar a alfabetização são excluídos/as desse processo. Ignora-se a vasta produção acadêmica em torno da temática da alfabetização que considera as especificidades das regiões brasileiras e os diferentes saberes necessários à alfabetização, que de forma alguma se reduzem às questões cognitivas, como mostra o estudo desenvolvido por Maciel (2019). As perspectivas históricas, linguísticas, sociais, antropológicas são silenciadas e desconsideradas nesse currículo, privilegiando-se saberes da ciência cognitiva para embasar as práticas de alfabetização.

Esse documento pretende atender a pelo menos duas urgências do momento contemporâneo. A primeira delas refere-se à necessidade apresentada nessa política curricular de eliminar o analfabetismo. Colocado como um problema recorrente na história brasileira, o analfabetismo tem sido combatido por meio de diferentes práticas e políticas. Todavia, parece que tais práticas não logram o resultado procurado. A PNA insere-se, 
portanto, nessa longa cadeia discursiva que vem tratando os/as analfabetos/as como um risco que é necessário gerir a fim de produzir ganhos para a população brasileira.

A segunda urgência histórica a que se pretende responder parece um pouco menos consensual do que a primeira. Trata-se da necessidade de estabelecer, para os diferentes âmbitos da educação e da sociedade, uma prática homogênea, que busca calar a diferença e reduzir ainda mais os direitos de diferentes grupos sociais. Assim, essa política insere-se também na cadeia que vem sendo produzida - e constantemente combatida - de silenciamento de grupos diversos e da instauração de um único modo de pensar. Nessa direção, Carvalho e Gallo (2020, p. 147) têm argumentado que, desde o rompimento institucional da democracia brasileira, em 2016, “emergiu uma enunciação visando combater as experiências e teorias educativas voltadas para as diferenças e as políticas afirmativas de inclusão social”. Parece-me que a PNA se insere nessa cadeia discursiva.

No que concerne às posições de sujeito produzidas, pode-se destacar que esse documento demanda "a criança alfabetizada”, o/a "alfabetizador/a que utiliza evidência científica em seu trabalho" e a "família corresponsável pela educação". Nesse processo, todos/as são pensados/as a partir de saberes da ciência cognitiva, que pretender estabelecer modos adequados de se relacionar com a alfabetização. É importante destacar que essa política já tem gerado outros produtos que visam detalhar o modo como esses indivíduos devem conduzir suas condutas. Assim, para os/as educadores/as foi criado, em 2020, o Programa de Formação “Tempo de Aprender”, curso on-line "que se destina principalmente a professores, coordenadores pedagógicos, diretores escolares e assistentes de alfabetização, sendo também proveitoso para gestores de redes educacionais e para toda a sociedade civil interessada”. Apresentado como “o programa sobre alfabetização mais completo da história do Brasil”, em 30 horas de formação a distância pretende-se instrumentalizar os/as docentes para colocarem em prática os saberes da PNA. ${ }^{7}$ Para as famílias, foi criado o Programa "Conta pra mim”, que conta com um livro disponível on-line intitulado "Conta pra mim - Guia de literacia familiar” e 40 vídeos $^{8}$ que ensinam às famílias como promover a literacia familiar e se corresponsabilizar pela educação de seus/suas filhos/as. Para as crianças, novas práticas de avaliação são estabelecidas, como o novo Sistema de Avaliação da Educação Básica (SAEB) que, entre outras medidas, pretende avaliar os/as estudantes a partir do segundo ano do ensino fundamental ${ }^{9}$.

O amplo investimento feito para garantir a produção dessas subjetividades, todavia, não é feito sem resistência. Afinal, não existe relação de poder que se estabeleça sem resistência (Foucault, 1995). Nesse momento, diferentes instituições sociais e educacionais se movimentam para dizer não a esse processo. A Associação Brasileira de Alfabetização (ABAlf), por exemplo, construiu um posicionamento em que critica o Programa Tempo de Aprender e a Política Nacional de Alfabetização. A Revista Brasileira de Alfabetização publicou um número especial em dezembro de 2019 com 23 análises em torno desse documento curricular que problematizam diferentes aspectos dessa política.

Não se trata, contudo, de uma resistência que simplesmente diz “não”. Trata-se de um convite para construir junto e por meio do diálogo uma política que abarque a diversidade existente em nosso país. Nesse momento de descaso com a educação e com a vida, a 
necessidade de pensar criticamente o momento que vivemos torna-se ainda mais urgente. É necessário resistir, não apenas para ser contra algo. É preciso resistir para que a prática “crie possíveis, nestes tempos de tantas políticas reacionárias” (Paraíso, 2016, p. 389), para que continuem a ser produzidos caminhos rumo a uma educação realmente igualitária e que afirme e produza a diferença.

\section{Notas}

1. Como exemplo, cito alguns programas e campanhas que tiveram como objetivo acabar com o analfabetismo: a Liga Brasileira Contra o Analfabetismo (1915), o Movimento Brasileiro de Alfabetização (MOBRAL, 1967), o Programa Alfabetização Solidária (1997) e o Programa Brasil Alfabetizado (2003). Há, também, diferentes programas de formação docente para a alfabetização, como o Profa (Programa de Formação de Professores Alfabetizadores - 2001), o ParFor (Plano Nacional de Formação de Professores da Educação Básica - 2009), o Pró-Letramento (2011), o PNAIC (Pacto Nacional pela Alfabetização na Idade Certa - 2012 a 2016).

2. Como exemplos, cito a Emenda Constitucional 95 (Brasil, 2016), que limitou os gastos públicos por 20 anos e os recorrentes cortes de bolsas de pesquisa de diferentes agências. No link a seguir há gráficos que mostram o desinvestimento em pesquisa ocorrido em nosso país nos últimos anos: https://vocesa.abril.com.br/carreira/cortesbolsas-pesquisa-ciencia/. Acesso em: 8 mai. 2020.

3. Um exemplo de diferentes falas que mostram a desqualificação de ditos da Ciência a respeito da COVID-19 pode ser visto no link a seguir: https://g1.globo.com/politica/noticia/2020/03/26/frases-bolsonaro-coronavirus.ghtml. Acesso em: 8 mai. 2020.

4. Na Constituição Federal, art. 210, estabelece-se que "Serão fixados conteúdos mínimos para o ensino fundamental, de maneira a assegurar formação básica comum e respeito aos valores culturais e artísticos, nacionais e regionais”. É esse preceito que justifica a criação de documentos como a Base Nacional Comum Curricular. Nesse sentido, conforme o texto constitucional, é dever do Estado definir “conteúdos mínimos”, mas contraria a liberdade pedagógica a definição sobre como ensiná-los ou a negação de outras formas de saber.

5. Importante registrar também que dois dos experts citados nos boxes “O que dizem os especialistas” são representantes proeminentes desse método. O professor Fernando César Capovilla, um dos autores do livro "Alfabetização: método fônico” (Capovilla; Capovilla, 2003), e o professor João Batista Araújo e Oliveira, presidente do Instituto Alfa e Beto, instituição que defende o uso do método fônico e que produz e divulga diferentes materiais voltados para essa dimensão. (Para mais informações, acesse: https://www.alfaebeto.org.br/category/politicas-educacionais/alfabetizacao/. Acesso em: 8 mai. 2020.)

6. Caldeira (2019, p. 173) mostra como opera em diferentes documentos curriculares o Dispositivo de Antecipação da Alfabetização, que busca "governar docentes e crianças para que a alfabetização se opere o quanto antes no processo de escolarização infantil”.

7. O curso está disponível em http://alfabetizacao.mec.gov.br/. São oito módulos de formação "Módulo 1 - Introdução; Módulo 2 - Aprendendo a ouvir; Módulo 3 - Conhecimento alfabético; Módulo 4 - Fluência; Módulo 5 - Vocabulário; Módulo 6 - Compreensão; Módulo 7 - Produção de escrita; Módulo 8 - Avaliação. Conforme pode-se perceber, os módulos correspondem quase que integralmente aos pilares da alfabetização descritos na PNA.

8. Disponível em: http://alfabetizacao.mec.gov.br/index.php?option=com_content\&view=article\&id=25:programa-contapra-mim\&catid=18:para-pais-e-responsaveis. Acesso em: 10 mai. 2020.

9. Informações disponíveis em: http://alfabetizacao.mec.gov.br/tempo-de-aprender. Acesso em: 10 mai. 2020.

\section{Referências}

ADAMS, Marilyn; FOORMAN, Barbara; LUNDBERG, Ingvar; BEELER, Terri. Consciência fonológica em crianças pequenas. Porto Alegre: Artmed, 2006. 
BRASIL. Constituição de República Federativa do Brasil de 1988. Brasília, DF: Presidência da República, 1988. Disponível em: <http://www.planalto.gov.br/ccivil_03/constituicao/constituicao.htm>. Acesso em: 10 mai. 2020.

BRASIL. PNA - Política Nacional de Alfabetização. Brasília: MEC; SEALF, 2019. Disponível em: $<$ http://alfabetizacao.mec.gov.br/>. Acesso em: 10 mai. 2020.

BRASIL. Emenda Constitucional n. 95, de 15 de dezembro de 2016. Brasília: Casa Civil, 2016. Disponível em: <http://www.planalto.gov.br/ccivil_03/constituicao/emendas/emc/emc95.htm>. Acesso em: 30 dez. 2020.

BRASIL. Apresentação Pacto Nacional pela Alfabetização na Idade Certa. Brasília: MEC, 2013.

BELLO, Samuel; TRAVERSINI, Clarice. O numerável, o mensurável e o auditável: estatística como tecnologia para governar. Educação e Realidade, Porto Alegre, v. 32, n. 2, p. 135-152, 2009. Disponível em: <https://seer.ufrgs.br/educacaoerealidade/article/view/8267/5535>. Acesso em: 30 dez. 2020.

BUNZEN, Clécio. Um breve decálogo sobre o conceito de “literacia” na Política Nacional de Alfabetização (PNA, 2019). Revista Brasileira de Alfabetização - ABAlf, Belo Horizonte, v. 1, n. 10 (Edição Especial), p. 44-51, 2019. Disponível em: <https://revistaabalf.com.br/index.html/index.php/rabalf/article/view/352>. Acesso em: 30 dez. 2020.

CALDEIRA, Maria Carolina da Silva; PARAÍSO, Marlucy Alves. Currículo e relações de poder-saber: conflitos e articulações entre o dispositivo de antecipação da alfabetização e o dispositivo da infantilidade. Currículo sem fronteiras [on-line], v. 17, n. 3, p. 769-794, set./dez. 2017. Disponível em: <http://www.curriculosemfronteiras.org/vol17iss3articles/caldeira-paraiso.pdf.> Acesso em: 10 mai. de 2020.

CALDEIRA, Maria Carolina da Silva. Dispositivo de antecipação da alfabetização e políticas curriculares contemporâneas: governando crianças e docentes. Linguagens, Educação e Sociedade, Teresina, ano 24, n. 43, set./dez., 2019. Disponível em: <https://revistas.ufpi.br/index.php/lingedusoc/article/view/9689>. Acesso em: 10 mai. 2020.

CAPOVILLA, Alessandra; CAPOVILLA, Fernando. Alfabetização: método fônico. São Paulo: Memnon, 2003.

CARVALHO, Alexandre Filordi de; GALLO, Silvio D. de Oliveira. Foucault e a governamentalidade democrática: a questão da precarização da educação inclusiva. Mnemosine, Rio de Janeiro, v. 16, n. 1, p. 146-160, $2020 . \quad$ Disponível em: <https://www.epublicacoes.uerj.br/index.php/mnemosine/article/view/52688/34300>. Acesso em: 30 dez. 2020.

ELLSWORTH, Elizabeth. Modos de endereçamento: uma coisa de cinema, uma coisa de educação também. In: SILVA, Tomaz Tadeu da. Nunca fomos humanos: nos rastros do sujeito. Belo Horizonte: Autêntica, 2001.

FISCHER, Rosa Maria Bueno. Foucault e a análise do discurso em educação. Cadernos de Pesquisa, São Paulo, n. 114, p. 197-223, nov. 2001. Disponível em: <http://dx.doi.org/10.1590/S0100$15742001000300009>$.

FOUCAULT, Michel. Arqueologia do saber. Rio de Janeiro: Forense Universitária, 1972.

FOUCAULT, Michel. O sujeito e o poder. In: DREYFYS H.; RABINOW, P. Michel Foucault: Uma trajetória filosófica para além do estruturalismo e da hermenêutica. Rio de Janeiro: Forense, 1995. p. 231-249.

FOUCAULT, Michel. A ordem do discurso. São Paulo: Loyola, 1996.

FOUCAULT, Michel. Resumo dos Cursos do Collège de France. Rio de Janeiro: Zahar, 1997.

FOUCAULT, Michel. História da Sexualidade II: o uso dos prazeres. São Paulo: Graal, 1998.

FOUCAULT, Michel. Vigiar e Punir. Petrópolis: Vozes, 1999. 
FOUCAULT, Michel. Soberania e disciplina. Organização e tradução de Roberto Machado. Microfísica do poder. Rio de Janeiro: Graal, 2000. p. 179-191.

FOUCAULT, Michel. História da Sexualidade I: a vontade de saber. São Paulo: Graal, 2006.

FRADE, Isabel Cristina Alves da Silva. Um paradigma científico e evidências a ele relacionadas resolveriam os problemas da alfabetização brasileira? Revista Brasileira de Alfabetização - ABAlf, Belo Horizonte, v. 1, n. 10 (Edição Especial), p. 15-25, jul./dez. 2019. Disponível em: $<$ http://abalf.org.br/revistaeletronica/index.php/rabalf/article/view/339>. Acesso em: 10 mai. 2020.

FRANGELLA, Rita de Cássia. Um Pacto curricular: Pacto Nacional pela Alfabetização na Idade Certa e o desenho de uma base comum. Educação em Revista, Belo Horizonte, v. 32, p. 69-89, 2016. Disponível em:

$<$ https://www.scielo.br/scielo.php?script=sci_arttext\&pid=S010246982016000200069\&lng=en\&nrm=iso\&tlng=en>. Acesso em: 10 mai. 2020.

LOCKMANN, Kamila. As reconfigurações do imperativo da inclusão no contexto de uma governamentalidade neoliberal conservadora. Pedagogía y Saberes, n. 52, p. 67-75, 2020. Disponível em: $<$ https://www.researchgate.net/publication/339073586_As_reconfiguracoes_do_imperativo_da_inclusao_ no_contexto_de_uma_governamentalidade_neoliberal_conservadora>. Acesso em: 30 dez. 2020.

MACIEL, Francisca Izabel Pereira. Onde estão as pesquisas sobre alfabetização no Brasil? Revista Brasileira de Alfabetização - ABAlf, Belo Horizonte, v. 1, n. 10 (Edição Especial), p. 58-59, jul./dez. 2019. Disponível em: <http://abalf.org.br/revistaeletronica/index.php/rabalf/article/view/376>. Acesso em: 10 mai. 2020.

MORAIS, Artur Gomes de. Análise crítica da PNA (Política Nacional de Alfabetização) imposta pelo MEC através de Decreto em 2019. Revista Brasileira de Alfabetização - ABAlf, Belo Horizonte, v. 1, n. 10 (Edição Especial), $\quad$ p. 66-75, jul./dez. 2019. Disponível em: <http://abalf.org.br/revistaeletronica/index.php/rabalf/article/view/357>. Acesso em: 10 mai. 2020.

MORTATTI, Maria do Rosário Longo. Os sentidos da alfabetização. São Paulo: Editora UNESP, 2000.

MORTATTI, Maria do Rosário Longo. A "Política Nacional de Alfabetização" (Brasil, 2019): uma "guinada” (ideo) metodológica para trás e pela direita. Revista Brasileira de Alfabetização - ABAlf, Belo Horizonte, v. 1, n. 10 (Edição Especial), p. 26-31, jul./dez. 2019. Disponível em: <http://abalf.org.br/revistaeletronica/index.php/rabalf/article/view/357>. Acesso em: 10 mai. 2020.

PARAÍSO, Marlucy Alves; RANNIERY, Thiago. Confrontos e resistências nas políticas curriculares e educacionais. Revista e-Curriculum, São Paulo, v. 17, n. 4, p. 1405-1413, out./dez. 2019. Disponível em: $<$ https://revistas.pucsp.br/curriculum/article/view/46538/30875>. Acesso em: 10 mai. 2020.

PARAÍSO, Marlucy. Currículo e mídia educativa brasileira: poder, saber, subjetivação. Chapecó, SC: Editora Argos, 2007.

PARAÍSO, Marlucy Alves. A ciranda do currículo com gênero, poder e resistência. Currículo sem Fronteiras, v. 16, n. 3, p. 388-415, set./dez. 2016. Disponível em: $<$ http://www.curriculosemfronteiras.org/vol16iss3articles/paraiso.pdf $>$. Acesso em: 10 mai. 2020.

PARAÍSO, Marlucy Alves. O currículo entre o que fizeram e o que queremos fazer de nós mesmos: efeitos das disputas entre conhecimentos e opiniões. Revista e-Curriculum, São Paulo, v. 17, n. 4, p. 1414-1435, out./dez. 2019. Disponível em: <https://revistas.pucsp.br/curriculum/article/view/45925/30886>. Acesso em: 10 mai. 2020.

ROCHA Juliano Guerra; OLIVEIRA, Marília Villela; SANTOS, Sônia Maria dos. A Política Nacional de Alfabetização - PNA: “do direito de criticar - do dever de não mentir ao criticar”. Revista Brasileira de Alfabetização - ABAlf, Belo Horizonte, v. 1, n. 10 (Edição Especial), p. 117-121, jul./dez. 2019. Disponível em <http://abalf.org.br/revistaeletronica/index.php/rabalf/article/view/374>. Acesso em: 10 mai. 2020. 
ROSE, Nikolas. Cérebro, self e sociedade: uma conversa com Nikolas Rose. Physis, Rio de Janeiro, v. 20, n. 1, p. 301-324, 2010. Disponível em: <https://www.scielo.br/scielo.php?script=sci_arttext\&pid=S010373312010000100016>. Acesso em: 10 mai. 2020.

ROSE, Nikolas. Governando a alma: a formação do eu privado. In: SILVA, Tomaz Tadeu (org.). Liberdades Reguladas. Petrópolis: Vozes, 1998. p. 30-45.

ROSE, Nikolas. Inventando nossos eus. In: SILVA, Tomaz Tadeu da. Nunca fomos humanos: nos rastros do sujeito. Belo Horizonte: Autêntica, 2001. p. 137-203.

SANTOS, Boaventura de Sousa. Um discurso sobre as ciências. Porto: Afrontamento, 2007.

SCLIAR-CABRAL, Leonor. Políticas Públicas de Alfabetização. Ilha Desterro, Florianópolis, v. 72, n. 3, p. 271-290, dez. 2019. Disponível em: <http://www.scielo.br/scielo.php?script=sci_arttext\&pid=S217580262019000300271\&lng=en\&nrm=iso>. Acesso em: $30 \mathrm{dez} .2020$.

SILVA, Tomaz Tadeu. As pedagogias psi e o governo do eu nos regimes neoliberais. In: SILVA, Tomaz Tadeu da. Liberdades Reguladas. Petrópolis: Vozes, 1998. p. 7-13.

SILVA, Tomaz Tadeu da. Documentos de identidade: uma introdução às teorias do currículo. Belo Horizonte: Autêntica, 2001.

SOARES, Magda. Alfabetização: a questão dos métodos. São Paulo: Contexto, 2018.

STREET, Brian. Os novos estudos sobre o letramento: histórico e perspectivas. In: MARINHO, Marildes. CARVALHO, Gilcinei. Cultura escrita e letramento. Belo Horizonte: Editora da UFMG, 2010. p. 33-53.

TRAVERSINI, Clarice Salete. Programa Alfabetização Solidária: o governamento de todos e de cada um. 2003. Tese (Doutorado em Educação) - Programa de Pós-Graduação em Educação, Faculdade de Educação, Universidade Federal do Rio Grande do Sul, Porto Alegre, 2003.

TRAVERSINI, Clarice Salete. Autoestima e alfabetização: o que há nessa relação? Cadernos de Pesquisa, São Paulo, v. 39, n. 137, p. 577-595, ago. 2009. Disponível em: $<$ https://www.scielo.br/scielo.php?script=sci_arttext\&pid=S010015742009000200012\&lng=en\&nrm=iso\&tlng=pt>. Acesso em: 10 mai. 2020.

\section{Correspondência}

Maria Carolina da Silva Caldeira: Doutora em educação pela Universidade Federal de Minas Gerais. Professora do Centro Pedagógico da UFMG e do Programa de Pós-Graduação em Educação: Conhecimento e Inclusão Social da mesma Universidade. É membro do Grupo de Estudos e Pesquisas em Currículos e Culturas (GECC/FaE/UFMG) e do Núcleo de Estudos e Pesquisas em Educação e Diversidade (NEPED/CP/UFMG).

Orcid: 0000-0003-0668-1989

E-mail: mariacarolinasilva@hotmail.com

Texto publicado em Currículo sem Fronteiras com autorização da autora 